\title{
Antioxidants in Hypoxic Ischemic Encephalopathy
}

\author{
Rathee AVS ${ }^{1}$, Prasad $\mathrm{PL}^{2}$
}

\begin{abstract}
Introduction: Perinatal asphyxia and related injuries are leading cause of morbidity and mortality in India. These babies are at risk to develop hypoxic ischemic encephalopathy (HIE) due to multiple organ including brain damage. The role of malondialdehyde (MDA) as a marker of free radical injury has been well established. Vitamin C and alpha Tocopherols have neutralizing effects on the free radicals. Considering these facts, it was decided to estimate serum MDA level in cases of HIE and the neutralizing effects of Vitamin C and Vitamin E. Material and Methods: The study was conducted in a tertiary care teaching hospital. Neonates with an Apgar score of $<6$ at 5 minutes and birth weight $>2500 \mathrm{~g}$ were included in the study. They were randomized into two groups. One group was given Vit $E$ and vitamin $C$ and the other was not given any of the anti oxidants. Serum MDA level were measured in both groups. Result: Serum MDA level was found to be increasing in both groups, but the increase was significantly higher in group II where antioxidants were not given. It was also found that serum MDA level was significantly low in antioxidants groups with HIE than those without antioxidants. Conclusion: Antioxidants supplementation in cases of HIE is associated with lesser production of free radicals and their neutralization is affected by antioxidants resulting into lesser damage to brain.
\end{abstract}

Key words: Antioxidants, birth asphyxia, hypoxic ischemic encephalopathy, MDA

\section{Introduction}

P erinatal asphyxia is a significant cause of neonatal mortality and morbidity. It is the brain which suffers the most because it utilizes more oxygen and energy for its function. The brain, therefore, is highly susceptible to asphyxia and hypoxic ischemic changes, which is brought on due to defect in oxidative phosphorylation and ATP production. There is also abnormal accumulation of electrolytes in cell leading to formation of reactive oxygen free radicals. This free radical oxygen reacts with biological molecules causing neuronal apoptosis and necrosis ${ }^{1}$.

Hypoxic Ischemic Encephalopathy (HIE) resulting due to perinatal asphyxia is characterized by necrosis of neurons of central
'Dr. AVS Rathee, MBBS, MD Resident. ${ }^{2}$ Dr. Prem Lochan Prasad, MBBS, MD, Professor. Both from the Department of Paediatrics, Shri Ram Murti Smarak Institute of Medical Sciences (SRMSIMS), Bareilly, U.P. India.

\author{
Address for correspondence: \\ Dr. AVS Rathee \\ C-103, Ganinath Kunj, Sector-5, Plot-1, Dwarka, \\ New Delhi 110075 \\ Telephone No: +917835938625 \\ E-mail: anant.mamc@gmail.com
}

\section{How to cite}

Rathee AVS, Prasad PL. Antioxidants in Hypoxic Ischemic Encephalopathy. J Nepal Paediatr Soc 2014;34(3):171-174.

doi: http://dx.doi.org/10.3126/jnps.v34i3.10122

This work is licensed under a Creative Commons Attribution 3.0 License.

\section{(c) (i)}

nervous systems. Oxidative stress plays a significant role in the mechanism of hypoxic ischemic damage to neuronal tissues. Serum Malondialdehyde (MDA) which is the end product of lipid peroxidation is a marker of oxidative stress ${ }^{2,3}$. Antioxidants play a defensive role in protecting tissues damage. Low level of antioxidants during oxidative stress leads to formation of free radicals $s^{4,5}$.

The aim of this study was to study effect of antioxidants in hypoxic ischemic encephalopathy(HIE) and the objectives 
were to estimate serum MDA level (as marker of free radicals) in HIE and to study neutralisation effects of antioxidants in cases of HIE compared with cases of HIE not exposed to antioxidants

\section{Materials and Methods}

The study was carried out to assess the role of antioxidants in cases of hypoxic ischemic encephalopathy. The most common and primary representative of dietary anti oxidants are Vit C, Tocopherols, and Carotenoid. Vit C and Vit E are nutrients which have free radical neutralizing properties ${ }^{4}$. This prospective case control study was conducted in paediatrics Department of a tertiary care rural teaching Hospital from January 2013 to December 2013. Term neonates with Apgar score of $<6$ at 1 minute and 5 minute after birth and weighing $\geq 2500$ g were included in the study. Babies having any congenital defects, preterm, post term, small for gestational age (SGA) and Large for gestational age and evidence of early onset sepsis or any other non asphyxiated illnesses likely to affect the newborn, were excluded from the study.

After initial stabilization, babies were shifted to NICU and were managed for hypoxic ischemic encephalopathy which also included oxygen inhalation. Three milliliters of peripheral venous blood was collected in a sterile plain vial within two hours of stabilization, at 24 hours of birth and on $5^{\text {th }}$ post natal day (at about 120 hours). Serum was separated from blood sample immediately by centrifugation at 1300 rpm for $10 \mathrm{~min}$ and stored in separate deionised vials at -20 degree $C$. The serum was analyzed for MDA level by Thio-barbituric acid reactive substances assay (T3RSA) method 6 .

The result were analysed by means of student's $t$ test by epi info 7 .

\section{Results}

Fifty two neonates were included in the study. They were randomly divided into two groups. There were 22 neonates in group I and 30 neonates in group II. Neonates in group I were given Vit E drops100 IU (Evion Drops, $50 \mathrm{IU} / \mathrm{ml}$, MERCK, Made in Usagaon Ponta Goa, India) and Vit C 200 mg (Syrup Limcee 100 $\mathrm{mg} / \mathrm{ml}$, Piramal Health Care Pvt Ltd, made in Solan, HP, India) after 2 hours of birth and Vit C 200 mg once daily orally for next 5 days. Babies in group II were managed for HIE without having been given any antioxidants. Serum MDA level was estimated at 2 hours of birth, at 24 hours and on $5^{\text {th }}$ postnatal day.

The mean MDA level within two hours of birth was $1.7347 \pm 0.38 \mu \mathrm{mol} / \mathrm{L}$ in group I and $1.925 \pm 0.53 \mu \mathrm{mol} / \mathrm{L}$ in group II. A rise in mean serum MDA was observed at 24 hours sample and again on $5^{\text {th }}$ post natal day in both groups (Table 1)

\section{Discussion}

Perinatal asphyxia is an important cause of fresh stillbirth and early neonatal death ${ }^{7}$. According to National Neonatal Perinatal database of India, 23\% of all neonates in our country suffer from asphyxia?. Multi organ involvement and neuronal necrosis is seen in $\mathrm{HIE}^{8}$. During early phase of brain injury due to HIE, a large cascade of events follows such as excitatory amino acid receptor over activation, impaired uptake of glutamate, increase in intracellular calcium concentration, activation of NO synthetase (NOS), activation of protein and DNA damage ${ }^{9,10}$.

During the reperfusion period, free radical production increases. Free radical damage is further aggravated in neonates due to immature antioxidant defenses ${ }^{11,12}$. Free radical can lead to lipid peroxidation as well as DNA and protein damage and can trigger

Table 1: Mean serum MDA level

\begin{tabular}{|c|c|c|c|}
\hline Serum MDA & $\begin{array}{c}\text { Group I Mean } \pm \text { SD } \\
(\mu \mathrm{mol} / \mathrm{L})\end{array}$ & $\begin{array}{c}\text { Group II Mean } \pm \text { SD } \\
(\mu \mathrm{mol} / \mathrm{L})\end{array}$ & p-value \\
\hline Mean at 2 hours & $1.7347 \pm 0.38$ & $1.925 \pm 0.53$ & $>0.05$ \\
\hline At 24 hours & $2.6127 \pm 0.15$ & $2.0301 \pm 0.64$ & 0.001 \\
\hline On 5th postnatal day & $5.2433 \pm 1.2856$ & $8.7211 \pm 2.2089$ & $<0.05$ \\
\hline
\end{tabular}

Table 2: Mean serum MDA level in HIE on 5th post natal day

\begin{tabular}{|c|c|c|c|}
\hline HIE Stage (n group I \& II) & Group I $(\mathbf{n = 1 9 )}$ & Group II $(\mathbf{n = 2 1 )}$ & p-value \\
\hline Stage I $(9,3)$ & $3.68 \pm 0.78 \mu \mathrm{mol} / \mathrm{L}$ & $7.23 \pm 1.01 \mu \mathrm{mol} / \mathrm{L}$ & $<0.005$ \\
\hline Stage II $(4,7)$ & $5.82 \pm 0.23 \mu \mathrm{mol} / \mathrm{L}$ & $7.92 \pm 0.79 \mu \mathrm{mol} / \mathrm{L}$ & $<0.005$ \\
\hline Stage III $(6,11)$ & $6.23 \pm 0.57 \mu \mathrm{mol} / \mathrm{L}$ & $11.08 \pm 2.17 \mu \mathrm{mol} / \mathrm{L}$ & $<0.005$ \\
\hline
\end{tabular}


apoptosis ${ }^{13,14}$. Anti oxidant level has been found to be low in $\mathrm{HIE}^{15}$. Frequent use of oxygen and ventilation has been proved to be life savings yet it is also proved that excess oxygen and deficiency of antioxidant may lead to generation of free radical and neuronal brain damage $e^{4,16}$.

Of the 22 neonates, five neonates had an Apgar score of three, seven had four and ten neonates had Apgar score of 5 at $5 \mathrm{~min}$. We compared serum MDA level as oxidative stress marker at birth (after 2 hours), at 24 hours and on $5^{\text {th }}$ postnatal day in both groups. There was no significant difference in serum MDA levels at two hours in both groups Table-1. Nivedita studied the serum level of oxidative stress markers and reported that serum MDA in cord blood was significantly higher among cases than controls. MDA level was significantly higher at 48 hours of life in cases than in control ${ }^{3}$.

There was progressive increase in level of serum MDA level in both groups at 24 hours age. Difference in increase was significant $(p<0.001)$. Serum MDA level on $5^{\text {th }}$ postnatal day was also found to be significantly lower in group I when compared with group II (table II). The concentration of MDA declined in interventional group where antioxidants were used and this decline was significant $(p<0.005)$.

Serum MDA level was also compared with stages of HIE in both groups. Three babies in group I and nine babies in group II died. The level was found to be progressively increasing as the severity of HIE increased though it was lower in group I babies than in group II. However, the differences were significant. Manoj et al also found increasing serum MDA level from stage I to stage III of HIE in their study ${ }^{10}$. Kumar et al studied 43 neonates with perinatal asphyxia who subsequently developed HIE. They found mean plasma MDA level in control group as $0.59 \pm 0.24 \mu \mathrm{mol} / \mathrm{L}$ whereas in HIE I it was $3.38 \pm 1.80 \mu \mathrm{ml} / \mathrm{L}, 2.98+1.92$ in stage II and $3.60+2.23$ in HIE stage III. Plasma MDA level in infants with HIE was higher compared with control subjects. Although there was a progressive increment in plasma level of MDA with increasing severity of HIE the differences were not statistically significant ${ }^{17}$. Saroj also found rising trend of serum MDA level with increasing severity of $\mathrm{HIE}^{18}$. Krimi et al studied 69 babies of HIE for serum MDA level and found significantly higher level of serum MDA in Sarnat grade II and III than in Sarnat grade I. He also found significantly higher level of serum MDA level in babies who died than those who survived ${ }^{19}$. However, Kumar did not find any correlation of serum MDA level with severity of $\mathrm{HIE}^{18}$.
It is concluded that antioxidant activity is low among cases of HIE. Antioxidant supplementation in newborn with birth asphyxia results in decrease in serum MDA level reducing neuronal death of newborn. Use of antioxidant for e.g. Vit C and Vit E appears to be in order to reduce neonatal deaths and morbidity. Serum MDA level and mortality and morbidity in HIE cases can be safely predicted based on higher serum MDA level. A long term study is required to predict cut off level of serum MDA level in various stages of HIE. The limitation of our study is that it is a short term study and babies have not been followed up for long term mortality, morbidity and developmental delay, it will be unwise to comment on protective aspect of these antioxidants in case of birth asphyxia.

\section{Conclusion}

We concluded that the antioxidant supplementation in the newborn with birth asphyxia results in decrease in the serum MDA levels which can be the bases for proposing early antioxidant supplementation in the management of birth asphyxia. Therefore continued use of antioxidants appears to be in order till we have a short and long term clinical study to substantiate these facts or prove it otherwise.

Limitations of the study are small sample size and short duration of follow-up. As we do not followed the patients for long, we are not in position to comment on the fact wheather decrease in the serum MDA levels of the cases as result of antioxidant supplementation does results in the changes in the morbidity and mortality associated with birth asphyxia. Further studies with similar objective, with longer follow-up duration and larger sample size are proposed.

\section{Acknowledgements: Nil \\ Funding: Nil \\ Conflict of Interest: None \\ Permission from IRB: Yes.}

\section{References}

1. Volpe JJ. Hypoxic ischemic encephalopathy: Clinical aspects. In Volpe JJ, ed Neurology of the newborn, Philadelphia Pa: Saunders Co;2000;332-382

2. Zitanova I, Simko M, Sumegova K, Korytar P, Maruniakova A, Demelova D et al. Markers of oxidative stress in umbilical cord in hypoxic newborns. J Pediatr Neonatol 2004;1;:NT1-NT4.

3. Mondal N, Bhat B V, Banupriya C, Koner BC. Oxidative Stress in Perinatal Asphyxia in Relation to Outcome. Ind J of Pediatr 2010;77:515-17 
4. Sharda B. free radicals: Emerging challenges in Environmental health research in Childhood and neonatal disorders. Int J Environ Res Public Health 2006;3(3);286-291.

5. Thorat VN, Suryakar AN, Sardeshmukh AS, Sarawade SS. Oxidants and antioxidants in hypoxic ischemic encephalopathy. Ind J Clin Biochem 2004;19:32-5.

6. Yagi K. Assay for lipid peroxide level and its clinical significance. In: Lipid peroxides in biology and medicine. Academic Press, New York, 1982;23342.

7. National Neonatology Forum NNPD Network. National Neonatal-Perinatal Database Report 2002-2003, New Delhi, Jan 2005.

8. Shah S, Mark Tracy, John Smyth. Postnatal lactate as an early predictor of short term outcome after interpartum asphyxia. J Perinatol 2004;24:16-20

9. Ray GN, Hussain SA, Dutta AK, Batra S. Lipid peroxidation and antioxidant status in asphyxiated neonates. Med Sci Res 1998;26:201-202

10. Manoj A, Rao KR, Bhat BS, Venkatesh C, Bobby Z. Oxidative stress induced DNA damage in Perinatal asphyxia. Curr Pediatr Res 2011;15(1):19-23.

11. Thirinnger K, Herbek A, Karlsson K, Rosen KG, Kjelimer I. Post asphyxial cerebral survivor in newborn sheep after treatment with oxygen free radical scavenger and a calcium antagonist. Pediatr Res 1987;22;62-6.

12. Inder TE, Graham P, Sanderson K, Taylor BJ. Lipid peroxidation as a measure of oxygen free radical damage in the very low birth weight infant. Arch Dis Child Fetal Neonatal Ed 1994;70 (2):F107-F111.13.

13. Mishra OP, Delivoria-Papadopoulos M. Modification of modulatory sites of NMDA receptor in the fetal guinea pig brain development. Neurochem Res 1992;17:1223-228.

14. Crawford MA, Sinclair AJ. Nutritional influences in the evolution of mammalian brain; In: Lipids, Malnutrition and the Developing Brain. Ciba Foundation Symposium, Amsterdam, Associated Scientific Publishers, pp 267-292.

15. Inder TE, Volpe JJ. Mechanism of Perinatal Brain Injury. Semin Neonatol 2000;J5(1):3-16.

16. McCord JN. Oxygen derived free radical in post ischemic tissues injury. N Eng J Med 1985;312;15163.

17. Kumar A, Mittal R, Khanna HD, Basu S. Free radical injury and blood-brain barrier permeability in hypoxic-ischemic encephalopathy. Pediatrics 2008;122(3):e722-7.

18. Singh SK, Dua T, Tandon A, Kumari S, Ray G, Batra S. Status of Lipid Peroxidation and Antioxidant enzymes in Hypoxic Ischemic Encephalopathy. Ind Pediatr 1999;36:659-68.

19. E Krimi, E Peker, O Tuncer, H Yapicioglu, N Narli, M Satar. Increased serum malondialdehyde level in neonates with hypoxic-ischemic encephalopathy: prediction of disease severity. IJ Int Med Res 2010;38(1);220-26. 